\title{
Constitucionalización del derecho o el regreso a los principios jurídicos ${ }^{*}$
}

\author{
NICOLÁS MASSMANN BOZZOLO \\ UNIVERSIDAD DE LOS ANDES
}

\begin{abstract}
Resumen: El autor plantea que el reciente fenómeno jurídico llamado constitucionalización del derecho puede ser comprendido desde una teoría principialista del derecho. La Constitución se presentaría aquí como el instrumento más eficaz para obtener vías de egreso de los sistemas legales cerrados. Como consecuencia, se produce una alteración en el orden de las fuentes del derecho y se explica el tránsito desde un derecho ontológico centrado en la norma y su aplicación meramente lógica hacia un derecho en movimiento, basado en la argumentación y en las reglas del discurso. Por último se revisa la posible relación que podría subyacer entre la constitucionalización y las normas iusnaturales, desechándose la posibilidad, al menos para la fase en que actualmente se encuentra el proceso en estudio.
\end{abstract}

Palabras Claves: Constitucionalización, Principialismo, Fuentes del Derecho, Argumentación, Normas Iusnaturales.

Abstract: The author raises the recent legal phenomenon called constitutionalization of the law, can be understood from a principialist theory of the law. The Constitution can be showed here as an instrument more effective to obtain ways to leave from closed legal systems. As a result, it is produced an alteration in the orden of the sources of the law, and it can explain the transition from a ontological Law, focused in the norm and in his solely logical to a Law in movement, based in the argumentation and in the rules of the discourse. At last it is review the possible relation that could underlie between the constitutionalization and the ius natural norms, rejecting the possibility, at least in the phase that is actually in study process.

Keywords: Constitutionalization, Principialism, Sources of the Law, Argumentation, Ius Naturale norms.

\section{Un cambio en el sistema de fuentes}

En el contexto del problema de los resultados jurídicos, y de modo especial en el de las resoluciones judiciales de fondo, toca al sistema de fuentes del derecho una funcionalidad de primer orden. Esto se manifiesta en que tanto la solución correcta -justa- a un caso, como también el standard de legitimidad del proceso de determinación de resultados jurídicos (sea lógico-silogístico, sea discursivo

\footnotetext{
*Versión escrita de la presentación realizada en el II Congreso Estudiantil de Derecho y Teoría Constitucional.
} 
o mediante procesos de argumentación jurídica), ante un conflicto de Derecho, estarán condicionados por la sistematización de fuentes que se encuentre consagrada en un ordenamiento concreto. Por lo mismo, se puede decir que la sistematización de las fuentes es un modo de expresar una valoración específica sobre la manera en que deberán darse curso jurídico a controversias de Derecho. Bajo esta acepción, no se puede sustraer la teoría de las fuentes de un determinado enfoque político del Derecho. Jorge Hübner metafóricamente constata el problema de las fuentes cuando señala: "El derecho es uno sólo, pero, como el mitológico Proteo, animado por distintas fuerzas, asume varias formas al manifestarse en la realidad social"1. Cada una de estas fuerzas (sociales o políticas, diremos), puntos de los que el derecho fluye, es lo que toma el nombre de "fuente del derecho". En todo ordenamiento existe una delimitación de dichas fuerzas creadoras acompañadas de un orden de prelación entre si. Curiosamente, su consagración es difusa, pues ninguna norma particular se encarga de consagrar la mencionada jerarquía de fuentes, al menos de un modo total ${ }^{2}$, por lo que son la cultura y la mentalidad jurídica dominante las que la determinarán. Históricamente el orden de las fuentes no siempre ha sido el mismo, ya que ha ido alternándose de diversos modos, según cuál sea la fuerza jurídica de atención prioritaria para una determinada época. La religión, la institución que ejerce el poder político o la autoridad de los iuris prudentes, ha dado paso a distintos modos de ordenar dichas fuentes: la de la primera jurisprudencia romana ${ }^{3}$, el derecho estatal legislado o el derecho romano clásico, respectivamente.

Desde la creación del Estado moderno hasta la primera mitad del siglo XX el poder estatal fue sin lugar a dudas el eje central, la primera fuerza en todo orden, también en el Derecho. El Estado monopolizó la producción jurídica y determinó de esta forma el orden de las fuentes de derecho, donde la ley pasaría a ocupar el puesto principal, relegándose el derecho jurisprudencial y la costumbre, prácticamente al ámbito de lo considerado extrajurídico. ${ }^{4} \mathrm{El}$ ordenamiento jurídico, entonces, tendió a ser visto como un sistema cerrado, y no faltaron escuelas que intentaron justificarlo desde sus mismas bases, procurando hacerlo cada vez más puro, cada vez más científico. ${ }^{5}$ El derecho, paradójicamente, terminó por alinearse con el poder político, tendiéndole un puente a los sistemas políticos totalitarios en los que la fuente de derecho principal ya no fue ley, sino la voluntad del Estado (del grupo dirigista) encubierta bajo proclamas de distinta índole. A pesar de todo, desde comienzos de la segunda mitad del s. XX hasta hoy, el panorama ha cambiado, lo mismo que la concepción doctrinal sobre las fuentes del derecho. Nuestro trabajo intenta determinar el papel que la Constitución y el derecho constitucional tuvieron y siguen teniendo en este nuevo modo de entender las fuentes del derecho.

Sin perjuicio de que un considerable sector de la doctrina siga sosteniendo la vigencia de un sistema cerrado cuyo centro es la ley, se percibe hoy una indesmentible corriente que aboga en favor ${ }^{6}$ de un sistema abierto capaz de superar la abstracción propia de la ley para dar lugar a un derecho fundado en la praxis o bien en las argumentaciones de justicia. Existe, con todo, cierta reticencia a reconocer

\footnotetext{
${ }^{1}$ HÜBNER G, JORGE, Introducción al Derecho, Ed. Jurídica de Chile, Colección de Manuales Jurídicos, Séptima edición, Santiago, 1995 , p. 139.

${ }_{2}^{2}$ En Chile puede extraerse el orden de las fuentes del Título Preliminar del Código Civil, en particular de los artículos 1, 2, y 3; del artículo 4 del Código de Comercio y del artículo 5 inciso 2 y 60 de la Constitución Política.

${ }^{3}$ D'ORS, ALVARO, Derecho Privado Romano, Eunsa, 9a edición, Pamplona, 1997, p. 50.

${ }^{4}$ Cfr. HERVADA, JAVIER, Introducción crítica al derecho natural, Colección jurídica de la Universidad de Piura, $1^{\text {a }}$ edición peruana, Piura, 1999, pp. 215 y ss.

5 ZAGREBELSKY, GUSTAVO, El derecho dúctil, Trotta, Madrid, 1995, p. 124. "Un sistema de derecho que pretendiese justificarse por si mismo 'se movería en el vacío', lo que resulta tanto más cierto con referencia a un derecho por principios. Esto explica el 'camino' histórico que las constituciones son capaces de recorrer, pese a permanecer inalteradas en su formulación literal".

${ }^{6}$ Una aproximación a la situación en la teoría analítica del derecho en CRISTÓBAL ORREGO S., De la ontología del derecho al derecho justo. Progresos recientes de la teoría analítica del derecho, en Revista Chilena de Derecho, Vol. 30 N², 2003, p.307.
} 
que detrás de toda teoría de las fuentes subyace una opción política no siempre explícita ${ }^{7}$, esto es, una decisión meta jurídica con efectos sobre el derecho. Como bien señala Orrego Sánchez: "Así como sería un error criticar el legalismo desconectado de la teoría política que lo sustentaba, sería una ingenuidad pretender que el aporte o el desarrollo post legalista de la Escuela de Viena era efectivamente una pieza de teoría jurídica pura, sin su propia y quizás inconsciente justificación ideológica. Pero el error más craso sería, a mi modo de ver, incurrir una vez más en el mismo error: considerar que una mentalidad jurídica ahora emergente - o una cultura jurídica que deseamos favorecer, de mayor iniciativa judicial para la defensa de los derechos naturales- viene a despojarse, ahora sí, de lastres ideológicos, cuando en realidad también es fruto de opciones políticas no siempre explícitas"8 En consecuencia, frente a los profundos cambios jurídicos que se viven hoy en el medio nacional, de compleja explicación por cierto, no se puede caer en la equivocación de entenderlos como sencillas adaptaciones del ordenamiento jurídico ante situaciones sociales nuevas o hasta hace poco no resueltas debidamente. Intentaremos aportar algunas consideraciones en torno a cuál ha sido, en concreto, dicho viraje ideológico, y cuál es el papel de la constitucionalización del derecho dentro de él

El fenómeno de la constitucionalización del derecho puede entenderse en el marco de la teoría de las fuentes, siempre y cuando se acepte por un lado, que la Constitución puede aplicarse directamente ${ }^{9}$, es decir, posee una fuerza vinculante que la determina como norma autónoma; y por otro, que es la norma suprema del ordenamiento ${ }^{10}$, no en el sentido piramidal-kelseniano, sino como la norma más fundamental, la opción jurídica más primaria. El impacto que produce la constitucionalización en el sistema de fuentes es denominado por Favoreu como "constitucionalización-elevación", significando que la producción jurídica tiene un vínculo de condicionamiento hacia la Constitución: "Antes de 1958, y como lo había demostrado magistralmente Carré de Malberg, el sistema de fuentes era esencialmente legislativo en el sentido que la ley definía su propio campo de aplicación tanto en cuanto al reglamento como acerca de la Constitución. Para parafrasear una terminología de derecho internacional, el legislador tenía "la competencia de su competencia"11. En el plano de los efectos colaterales esta nueva tendencia ha dado lugar, por ejemplo, a que cierta doctrina jurisprudencial sostenga la facultad de excusarse del juez de aplicar la ley en una circunstancia donde a su juicio debiera primar la disposición constitucional ${ }^{12}$, aún cuando el régimen de control constitucional previsto en la misma Constitución no sea el desconcentrado. Otro ejemplo lo constituye la interpretación amplísima sobre la nulidad de derecho público que admite su procedencia con efectos inmediatos -ipso iure-, y desde el mismo momento en que se dicta la norma considerada como inconstitucional, toda vez que contenga elementos contrarios a las disposiciones o principios constitucionales. ${ }^{13} \mathrm{O}$ también, la menos explorada doctrina de la inconstitucionalidad por omisión del legislador, tesis audaz que sólo puede ser entendida a la luz del nuevo rol que se le asigna a la Constitución en el sistema de fuentes. Como señala Cea: "Fluye de ello que la inconstitucionalidad por omisión no se refiere sólo al transcurso prolongado de tiem-

\footnotetext{
${ }^{7}$ ORREGO S., CRISTÓBAL, La cultura jurídica interna: ¿HHacia el colapso de la pirámide?, en Anuario de Filosofía Jurídica y Social, Valparaíso, 2002, p. 463.

${ }^{8}$ Idem.

${ }^{9}$ ORREGO S., CRISTÓBAL, La cultura..., p. 474.

${ }^{10}$ PEREIRA MENAUT, ANTONIO CARLOS, Teoría Constitucional, Ed. Conosur, Santiago, 1998, p. 19.

${ }^{11}$ FAVOREU, LOUIS, La constitucionalización del derecho, en Revista de Derecho Universidad Austral, Vol. XII, 2001, p. 39-40.

${ }_{12}$ Nos referimos a la doctrina del juez Carlos Cerda surgida con motivo del procesamiento de ciertos militares en causas de derechos humanos. Entonces llegó a afirmar lo siguiente: “a la ciudadanía podría interesarle lo siguiente: que los jueces de este tiempo, es decir, de comienzos del s. XXI, no están llamados como en la época de la revolución francesa, nada más que aplicar la letra de la ley, sino que están llamados a adoptar en sus actuaciones el principio de legalidad y de reserva constitucional. Lo que querrá decir que cualquier ley que se dicte no ha de ser vinculatoria para los jueces, sino en la medida en que ellas mismas sean dictadas conforme a los derechos esenciales que la Constitución chilena ordena resguardar (...)”. Cfr. Diario El Mercurio del 8 de julio de 2003.

${ }^{13}$ Cfr. SOTO KLOSS, EDUARDO, Derecho Administrativo, Bases fundamentales. Vol. II: El principio de juridicidad, Ed. Jurídica de Chile, Santiago, 1996, pp. 163-179.
} 
po sin que el legislador dicte las normas que vuelven operativa a la Constitución, sino que, además y tal vez con mayor frecuencia y prácticamente entendido el asunto, tal inconstitucionalidad versa sobre la dictación de de normas legales insuficientes, incompletas y defectuosas, como también, acerca de la aprobación de disposiciones legales inobjetables, pero sin financiamiento ni recursos humanos idóneos para llevarlas -como escribió Roscoe Pound- de los libros a la acción real"14 La referencia constitucional, tanto para la creación como para la interpretación del derecho, pasa a ser de esta forma, un requisito ineludible para el operador jurídico. Así lo impone la misma carta, lo ha tendido a entender así también una parte importante de la doctrina y, como luego veremos, se ha llegado a esta práctica por la necesidad de ampliar los márgenes específicos del razonamiento judicial, como igualmente los del razonamiento jurídico general.

\section{Emergente supremacía de los principios constitucionales}

Las nuevas perspectivas que comienzan a plantearse en torno a la doctrina tradicional de las fuentes, siempre centrada en la ley, son imputables, en gran medida, a la renovación doctrinal y jurisprudencial de la teoría de los principios jurídicos. Por razones que no es del caso analizar, el creciente interés por la protección de los derechos fundamentales, ha servido como catalizador de dicho proceso crítico, toda vez que se ha comprobado por la misma práctica la insuficiencia del recurso a la mera legalidad con el fin de alcanzar garantías suficientes de protección ${ }^{15}$. La decisión jurídica reclama de otros elementos para llegar a ser verdaderamente "justa", o en otras palabras, que la sola ley ya no es suficiente para el juez: "Ya nadie puede... afirmar en serio que la aplicación de las normas jurídicas no es sino una subsunción lógica bajo premisas mayores formadas abstractamente"16. En igual sentido afirma Alexy: "La decisión jurídica, que pone fin a una disputa jurídica, expresable en un enunciado normativo singular, no se sigue lógicamente, en muchos casos, de las formulaciones de las normas jurídicas que hay que presuponer vigentes, juntamente con los enunciados empíricos que hay que reconocer como verdaderos o probados" ${ }^{17}$. Zagrebelsky, por su parte, sostiene en torno a la equidad ${ }^{18}$ : "La separación positivista entre jurisdicción de equidad y jurisdicción de derecho respondía a la presupuesta separación entre las dos nociones y servía para identificar el derecho sólo con la ley"19. Esta afinidad doctrinal acerca de la superación de una etapa de la ciencia del derecho en que se le entendió como ciencia únicamente teórica y pura, no es, sin embargo, de tal magnitud como para no admitir diferencias entre sí, especialmente en torno a la naturaleza y fundamentación de las normas o principios considerados "no escritos". 20

Este diagnóstico crítico de la situación jurídica contemporánea ha encontrado su correlativo práctico en diversas instituciones jurídicas que reconocen dichos principios "no positivos" como recursos necesarios para una actividad judicial que tienda a la justicia concreta. Es así como el proceso

${ }^{14}$ CEA, JOSÉ LUIS, La constitucionalización del derecho, en Revista de Derecho Público, No 59, 1996, p. 14.

${ }^{15}$ Cfr. OLLERO, ANDRÉS, Interpretación del derecho y positivismo legalista, Editoriales de Derecho Reunidas, Madrid, 1982, p. 38.

${ }^{16}$ LARENZ, KARL, Metodología de la ciencia del derecho, citado en ALEXY, ROBERT, Teoría de la argumentación jurídica, Centro de Estudios Constitucionales, Madrid, 1997, p. 23.

17 ALEXY, ROBERT, op. cit., p. 23. El autor enumera, a continuación, cuatro razones de por qué no es posible la decisión judicial en torno a normas abstractas.

${ }_{18}$ Para los efectos de la argumentación la referencia vale considerando la equidad como elemento "no positivo" necesario para la decisión judicial, sin perjuicio que entre equidad y principios jurídicos exista una estrecha relación.

19 ZABREBELSKY, GUSTAVO, op. cit., p. 148.

${ }^{20}$ A modo de ejemplo, Zabrebelsky, profundo defensor de un derecho de principios tiende a desechar la posibilidad de que se encuentren fundamentados en el derecho natural, en cambio, JOHN FINNIS, en Ley natural y derechos naturales, Buenos Aires, Abeledo-Perrot, 2001, p. 313, desarrolla una defensa de los principios generales como expresiones determinadas de normas de derecho natural. Un interesante trabajo, sobre todo acerca de las corrientes principialistas no positivistas, puede encontrarse en García Figueroa, Alfonso, Principios y positivismo jurídico, Madrid, Centro de Estudios Políticos y Constitucionales, 1998. 
de constitucionalización del derecho debe entenderse dentro de esta corriente general, siendo, probablemente, la vía más inmediatamente eficaz para obtener cursos de egreso de los sistemas de derecho "cerrados" por la lógica del legalismo. En efecto, además de la constitucionalización la doctrina y jurisprudencia han buscado otras vías prácticas para salir del derecho ontológico y pasar al derecho justo ${ }^{21}$. En el campo del Derecho Internacional Público ha tenido un notable desarrollo la doctrina de las normas de ius $\operatorname{cogens}^{22}$, las que han servido, en el plano supranacional, para sortear las barreras del derecho interno, ya que se imponen a los Estados sin importar a la comunidad internacional la aceptación particular que pueda hacer de ellas el Estado al que se aplican. En materia de evaluación de pruebas otorgadas se ha tendido a reconocer en ciertas normativas la posibilidad de aplicar las reglas de la sana crítica; es el caso del nuevo Código Procesal Penal.

Este contexto general permite identificar de mejor forma la verdadera naturaleza con la que se corresponde el fenómeno en estudio, que a nuestro juicio es la de instrumento para salir del sistema de fuentes escalonado y rígido, hoy predominante, para pasar a un sistema donde el discurso jurídico y la argumentación judicial tengan real acogida. La pregunta es por qué se le atribuye a la sede constitucional la virtud de ampliar los márgenes de "lo jurídico". Básicamente, debido a la aceptación que ha tenido tanto entre los autores como en la jurisprudencia la teoría de su fuerza vinculante. Por medio de ella los principios de derecho, implícitos o explícitos, que la Constitución contiene pueden y deben ser aplicados por todos los órganos del Estado ${ }^{23}$, y entre ellos, de manera especial por la judicatura. Para que se produzca esto, generalmente no fueron necesarias modificaciones constitucionales ya que el centro del problema radica sobre todo en un viraje en la opción política que anima a los operadores del derecho que los ha llevado a buscar en el texto constitucional y en el derecho constitucional las reservas de principio justiciables que la sola lex no solamente no era capaz de aportar, sino más bien, hacía de difícil aplicación. En efecto, "No estamos ante nuevas normas contenidas en las fuentes formales del derecho (chileno), sino ante un nuevo derecho de creación doctrinal, que transforma el modo de comprender las normas escritas, dando origen a un derecho consuetudinario que no deriva su validez del derecho escrito (...)." ${ }^{44} \mathrm{El}$ viraje cultural ha significado, entre otras cosas, un interés en las formas de protección de los derechos de las personas otorgando al juez atribuciones de interpretación y aplicación de un derecho que se considera más sustantivo que procedimental ${ }^{25}$.

El mencionado (ab)uso de la Constitución como punta de lanza en este proceso de "desformalización" 26 de las fuentes del derecho se debe también a la gran cantidad de normas de principio que una Constitución suele acoger. Por su misma naturaleza, la Constitución admite un margen más amplio de interpretación dada la indeterminación de muchos de sus principios. La emergente relevancia de los mismos y su influencia a todo nivel, han llevado a que en los últimos años el derecho constitucional como campo de investigación haya surgido notablemente, pudiéndose decir con propiedad que es justamente en el derecho constitucional donde hoy se llevan a cabo las discusiones doctrinales más relevantes, ya no políticas, sino jurídicas.

\footnotetext{
${ }^{21}$ Cfr. ORREGO S., Cristóbal, De la ontología..., pp. 397-320.

${ }^{22}$ Cfr. BENADAVA, SANTIAGO, Derecho Internacional Público, Ed. Conosur, séptima edición, Santiago, 2001.

${ }^{23}$ Cfr. Artículo 6 de la Constitución Política de la República de Chile

${ }^{24}$ ORREGO S., CRISTÓBAL, La cultura jurídica..., p. 470.

${ }^{25}$ Cfr. Idem.

${ }^{26}$ CORREA G., RODRIGO, “¿Vulgarización por constitucionalización?”, en Revista de Derecho y Humanismo, Universidad de Chile, Vol XI, 2005, en imprenta. Allí expresa su disconformidad con las argumentaciones desinstitucionalizadas propias de este proceso. Señala: "En el fondo se trata de un espíritu antiformalista, que pone las expectativas económicas o morales por sobre las categorías jurídicas formales. Para este espíritu, las decisiones judiciales sólo pueden ser evaluadas por su impacto puntual a dichas expectativas. Los fundamentos dejan de importar, sólo interesan los resultados". El argumento pierde validez si se consideran las reglas de argumentación que en la fundamentación de soluciones jurídicas deben tenerse en cuenta, en especial, en las argumentaciones dogmáticas. Vid. Alexy, Robert, op.cit.
} 
También conviene hacer referencia a la modificación que el mismo Estado ha soportado con motivo de esta nueva orientación jurídica basada en normas constitucionales de principio. Zagrebelsky la describe así:" La ley, por primera vez en la época moderna, viene sometida en una relación de adecuación, y por tanto de subordinación, a un estrato más alto de derecho establecido por la Constitución. De por sí, esta innovación podría presentarse, y de hecho se ha presentado, como una simple continuación de los principios del Estado de derecho que lleva hasta sus últimas consecuencias el programa de la completa sujeción al derecho de todas las funciones ordinarias del Estado, incluida la legislativa (...). Sin embargo, si de las afirmaciones genéricas se pasa a comparar los caracteres concretos del Estado de derecho decimonónico con los de Estado constitucional actual, se advierte que, más que una continuación se trata de una profunda transformación que incluso afecta necesariamente a la concepción del derecho"27. Por su parte, Pereira Menaut concluye: "A primera vista puede parecer que colocar la sumisión de la potestad política en la Constitución, y no sólo en la ley, no es más que subir un peldaño en la pirámide de la normas y que, por los tanto, no implica para el Imperio del Derecho ningún cambio de naturaleza sino sólo de grado. No es así, porque si cambiamos el Derecho al que se somete el poder, cambiará el Imperio del Derecho (...). No hubo un paso de frontera claro, pero la suma de los impactos de los derecho fundamentales, los valores, los principios y la sumisión a la Constitución produjo una modificación importante"28.

\section{Evolución a tres tiempos del pensamiento constitucional}

Si es que hoy día somos testigos de lo que podríamos llamar un auge del derecho constitucional, en el sentido arriba descrito, bien vale la pena hacer una revisión histórica de la evolución del pensamiento constitucional a partir de sus mismos orígenes. En concreto nos interesa solamente la evolución de lo que podríamos denominar "mentalidad constitucional", un modo de entender la relación entre la sociedad y el poder (estatal, específicamente) que tuvo un comienzo y, probablemente, como todo proceso histórico, tendrá también un final. ${ }^{29}$

\section{a) Elprimer pensamiento constitucional ${ }^{0}$}

Pereira Menaut describe esta primera etapa del constitucionalismo haciendo uso, por metodología, de cuatro presupuestos que en su opinión se encontraban presentes al momento de nacer esta corriente de pensamiento política y que precisamente, fueron esenciales para su misma génesis: "Como todas las instituciones jurídico-políticas, la Constitución no nació por generación espontánea, ni como una planta sin tierra, sino que, muy al contrario, su nacimiento y crecimiento fueron precedidos y posibilitados por unos presupuestos o bases de diversa índole, desde culturales hasta económicos". ${ }^{31}$ Tales presupuestos se pueden agrupar en:

\footnotetext{
27 ZAGREBELSKY, GUSTAVO, op. cit., p. 34.

28 PEREIRA MENAUT, ANTONIO CARLOS, Rule of Law o Estado de Derecho, Marcial Pons Ediciones Jurídica y Sociales, Madrid, 2003, p. 76-77.

${ }^{29}$ Cfr. PEREIRA MENAUT, ANTONIO CARLOS, Teoría Constitucional, p. 451 y ss. Es interesante una observación hecha por el autor: "Desde otro punto de vista, también se podría argumentar que, si nada es eterno, ¿por qué la Constitución ha de seguir siendo reverenciada, varios siglos después de su nacimiento y en circunstancias muy distintas? ¿Por qué hemos de hacer nuestros los objetivos de una burguesía de hace varios cientos de años?" Sin embargo, se trata de preguntas formulada con el fin de dar paso a una aguda defensa de la Constitución como institución jurídica-política y al constitucionalismo como corriente de pensamiento todavía vigente.

${ }^{30}$ Seguiremos aquí la tesis de los presupuestos de Antonio Carlos Pereira, Teoría constitucional... cit., p. 46 y ss.

${ }^{31}$ Idem., p. 46.
} 


\section{a) Presupuestos jurídicos:}

"La Constitución nació sobre la base de una tradición jurídica específicamente occidental", es decir, con unas características determinadas que en parte subsisten hasta hoy, como podrían ser la idea de que el Derecho debe dominar sobre la realidad y no los hechos determinarlo; que el poder es limitado y su principal límite no es fáctico, sino jurídico, también que existe una cierta juridicidad universal, principios de derecho que comparten todos los pueblos, por estar arraigados en la misma esencia del hombre y la sociedad, es decir "nadie discutía la existencia del Derecho Natural"32

\section{b) Presupuestos éticos:}

Hoy nos encontramos en un momento de profundos desacuerdos éticos, y las propuestas sobre el bien de hombre no sólo son distintas entre sí, sino que muchas de ellas contradictorias e incompatibles. Costaría pensar que con estas bases hubiese podido surgir el constitucionalismo primitivo, forjado sobre una base de notable concordancia moral. "La Constitución se formó sobre la base de un rígido puritanismo que producía buenos ciudadanos educados en la dura ética del self-control y dotados de muchas virtudes cívicas (y personales). Había general aceptación de la ética cristiana, a pesar de la diversidad de confesiones religiosas (...) Particularmente relevantes fueron, a este propósito, las ideas cristianas sobre la libertad, dignidad, e igualdad de la persona humana": 33

\section{c) Presupuestos fundamentales: el "acuerdo en lo fundamental":}

El entorno en el que tuvo su origen el movimiento constitucional no discutía acerca de la existencia de determinada instituciones y la importancia de muchas de ellas; para esa gente se trataba de cuestiones evidente, y se podría decir que había unanimidad moral acerca de su trascendencia para la eficacia de la Constitución. De este modo, había un indiscutido acuerdo en: "el orden del mundo, la existencia de la naturaleza humana básica invariable, los aspectos esenciales de la ética con su clasificación de los bueno y lo malo (...) Si el mundo no tiene su propio sentido, carecemos de argumentos contrarios al voluntarismo de la ley o de la convención, y tampoco podemos encontrar un fundamento sólido para dos aspectos esenciales a la idea de Constitución, a saber: el imperio del Derecho sobe el poder y los derechos humanos anteriores a toda ley". 34

\section{d) Presupuestos políticos:}

Entonces se compartían algunas ideas básicas (nunca todas) sobre la actividad política, lo que puede entenderse, también, como que no todo en política podía estar sujeto a cambios. Por ejemplo, se concordaba en "el individualismo activo, en vez de la moderna masificación"; "la desconfianza hacia el poder, considerado por principio como algo malo en sí, que debe ser frenado y limitado aun cuando estuviese en manos de un gobernante amistoso o bien intencionado"; "la idea de que el poder es, por definición, cosa limitada", y "la idea de que el Estado y la sociedad no coinciden" 35 .

El primer pensamiento constitucional, basado en esta serie de presupuestos no directamente constitucionales, fue bastante sencillo y ajeno a cualquier clase de tecnicismo, que por lo demás no interesaba para los efectos que se perseguían, que no eran más que los de lograr contener las influencias de un poder político cada vez mayor. "Todo aquel conjunto de ideas, creencias, actitudes mentales

\footnotetext{
${ }^{32}$ Idem., p. 47-48.

${ }^{33}$ Idem., p. 48.

${ }^{34}$ Idem., p. 49.

${ }^{35}$ Idem., p. 49.
} 
y presupuestos, en el cual el constitucionalismo se albergaba, ha sido sustituido por una concepción universal, pero poco más que formal, y por una perfección y sofisticación en los aspectos accidentales de la Constitución (...) antes nunca lograda -y quizás tampoco muy buscada. Hoy no es infrecuente encontrar constituciones tan formalmente espléndidas como puramente semánticas, ni constituciones que, edificadas obre la inexistencia de los presupuestos mencionados, alcanzan, sin embargo, niveles de refinada filigrana en materias de detalle (...) Por estas razones, Friedrich y Loewenstein, entre otros, lamentan el presente debilitamiento de lo que el segundo llama "sentimiento constitucional" 36

Después de todo, conviene sacar algunas ideas esenciales acerca del concepto que en un comienzo se tenía sobre la Constitución, como también cuál era su finalidad más inmediata. Mario Justo López atribuye a este primer constitucionalismo un finalidad "de neto corte personalista y que se puede expresar diciendo que consiste en erigir la 'dignidad de la persona humana' -de toda persona humana- en "supremo valor terrenal" 37 . En este mismo contexto de recurrir a los orígenes del movimiento, Ignacio De Otto afirma: "Que una sociedad tenga Constitución, que un Estado sea constitucional, significa, ante todo, que en él la organización de los poderes responda a un determinado fin, el aseguramiento y garantía de la libertad de los ciudadanos (...), Constitución designa algo más que una norma jurídica: la propia organización del Estado que obedece a determinados principios, esto es, que responde a una determinada 'esencia"' 38 . La sencillez del primer planteamiento constitucional permitió, al mismo tiempo, entender y llevar a la práctica su también sencillo propósito: frenar el poder a través del Derecho. Ello implicó reconocer que la Constitución era entendida como algo más que un texto del que se desprendían competencias y mediante el cual se organizaba el aparato estatal. Esto último aunque verdadero, no agota ni menos abarca toda su función. La Constitución también fue entendida como la representación del derecho universal. Quien sobrepasaba la Constitución se situaba al margen de la juridicidad; el poder que la infringía declaraba no reconocer límites, y no solamente haberse excedido ocasionalmente en algún aspecto de competencias. "El límite del poder va a ser el Derecho, por lo que la naturaleza de la Constitución se presenta revestida de carácter jurídicoformal"39.

\section{b) Siglos XIX y comienzos del XX:}

A lo largo de estos siglos se produjo un viraje en el centro de atención del constitucionalismo, de modo que su objeto de protección ya no fue tanto la persona y sus derechos inherentes, sino más bien la organización del Estado, la distribución de competencias, y la estructuración del panorama político. En efecto, " $[\mathrm{L}]$ o característico del fenómeno constitucionalista moderno no estriba, por lo tanto, en la mera existencia en el Estado de una ley fundamental que fije su organización, realidad ineludible de todos los lugares y tiempos, ni aún en que la sociedad política tome conciencia de dicha realidad, muy anterior también a tal fenómeno, ni, en fin, en que se tracen en documentos escritos los rasgos de la ordenación básica. La novedad e importancia del fenómeno constitucionalista se halla en la tendencia que se extiende entre las naciones de expresar solemnemente la voluntad de organizarse sobre los marcos que se precisan en documentos escritos en que se determinan la estructura del Estado, sus órganos, los mecanismos del gobierno y las garantías de las libertades ciudadanas". ${ }^{40}$

Este afán racionalizante de la convivencia política unido a las emergentes ideologías omniabarcantes hicieron que el pensamiento constitucional de la época se enfocara más en lo abstracto y en lo

\footnotetext{
${ }^{36}$ Idem., p. 49-50.

${ }^{37}$ JUSTO LÓPEZ, MARIO, Manual de derecho político, Ed. Kapelusz, Buenos Aires, 1973, p. 376.

${ }^{38}$ DE OTTO, IGNACIO, Derecho Constitucional. Sistema de fuentes, Ed. Ariel, Segunda edición, Barcelona, 1988, p. 12.

${ }^{39}$ PEREIRA MENAUT, ANTONIO CARLOS, Teoría Constitucional, p. 16.

${ }^{40}$ SILVA BASCUÑAN, ALEJANDRO, Tratado de Derecho Constitucional, Tomo I, Ed. Jurídica de Chile, Segunda edición, Santiago, 1997, p. 84-85.
} 
programático, que en la protección concreta de los ciudadanos. El crecimiento de los aparatos estatales y las revoluciones internas colaboraron también a que las cartas fundamentales más que constituciones de los ciudadanos pasaran a ser constituciones de los estados. Podría decirse que durante esta época se dio mayor énfasis a la dimensión política de la Constitución que a su vertiente jurídica, pues en ella se reflejaban los cambios estatales que por entonces se promovían a la vez que se aprovechaba de trazar directrices políticas en el mismo texto. En este sentido sirve tener en cuenta las expresiones de Lasalle, padre de la llamada escuela sociológica, al intentar responder a la pregunta ¿Qué es una Constitución?: "Los problemas constitucionales no son primariamente problemas de derecho, sino de poder: la verdadera Constitución sólo reside en los factores reales y efectivos de poder que en ese país rigen; y las constituciones escritas no tienen valor ni son duraderas más que cuando dan expresión a los factores de poder imperantes en la realidad social" 41 .

A este nuevo centro de atención del constitucionalismo, el Estado en todo su esplendor soberano (contradictorio, por cierto, con el concepto originario), se debe añadir la fuerte influencia que la corriente ideológica del positivismo jurídico tuvo a fines del siglo XIX y comienzos del XX. Reduciendo el concepto del derecho a la sola norma positiva, y más aún, positiva y legislada, el positivismo aspiró a reordenar la estructura jurídica a partir de la Constitución, que desde entonces pasará a ser un documento ideológicamente neutro y legitimador del derecho creado, en tanto que formalmente sea "producido a partir de la Constitución" 42 . Afirma García Pelayo que para dicha corriente "la Constitución era el fundamento de la totalidad del orden jurídico y de la actividad estatal, principio completamente acorde y en necesaria relación lógica formal y vital con la esencia del Estado de Derecho. No hay más orden en la vida estatal que el legal y objetivo, valedero para todos los casos y al que quedan vinculados los órganos superiores del Estado; ahora bien, el puesto de todo este orden es la Constitución entendida como sistema de normas jurídicas: ella es 'ley fundamental', 'ley suprema', 'punto de Arquímedes de la legalidad estatal' (Burckhardt)", y así "La Constitución queda reducida a un elemento técnico para la comprensión de la unidad y producción del orden jurídico, y el Derecho constitucional a la exposición de un sistema de competencias". ${ }^{43}$

Como ya se dijo anteriormente, el positivismo tendió a blindar a la Constitución de cualquier elemento ideológico que empañara su pureza conceptual. De este modo es que las constituciones del positivismo fueron pobres en lo que se refiere a principios vinculantes para la legislación producida, como también para la interpretación general del derecho y los conflictos. ${ }^{44}$ ¿Qué significó este hecho para pensamiento constitucional de la época? Simplemente que era precisa la creación de un órgano al que se le encomendara de forma concentrada la revisión de los procesos de legislación "conforme a la Constitución", como también de la preservación de la estricta jerarquía normativa de tipo piramidal, cuya cúspide era naturalmente la Constitución. Nacieron así los llamados tribunales constitucionales. Con todo, el constitucionalismo de entonces no se apartó del pensamiento jurídico positivista que entonces predominaba, más bien se correspondió con este. Y como consecuencia de ello, la aplicabilidad de la Constitución pasó al olvido, quedándose en un puro documento procedimental, ya que a la ley, único derecho vinculante, no cabía menos que ser aplicada lógicamente por los jueces, aspirando a dejar en el olvido el problema de la interpretación y la subjetividad judicial. ${ }^{45}$ Sarcásticamente recuerda Ramón Domínguez los efectos que a nivel constitucional se producían con este tipo de razonamien-

\footnotetext{
${ }^{41}$ LASALLE, FERDINAND, ¿Qué es una Constitución?, Editorial Temis, Bogotá, 1992, p. 50.

${ }^{42}$ Una visión completa de la influencia del positivismo jurídico en el ordenamiento jurídico en CARLOS J. ERRÁZURIZ M., Introducción crítica a la doctrina jurídica de Kelsen, Ed. Jurídica de Chile, Santiago, 1987.

${ }^{43}$ GARCÍA PELAYO, MANUEL, Derecho constitucional comparado, Alianza Editorial, Madrid, 1987, p. 56.

${ }^{44}$ Cfr. LOEWENSTEIN, KARL, Teoría de la Constitución, Ed. Ariel, Segunda edición, Barcelona, 1986, p. 212. "Estas constituciones ideológicamente neutras se proponen, sin ningún tipo de preferencia ideológica, ofrecer un cuadro funcional dentro del cual las fuerzas sociales y políticas de la comunidad deberán enfrentarse en libre concurrencia (...)”.

${ }^{45}$ Cfr. OLLERO, ANDRÉS, op. cit.., p. 129 y ss.
} 
tos: "hasta hace unos veinte años, jamás los abogados en Chile requeríamos el uso de la Constitución en nuestros casos, así no fueran penales. Estamos seguros que la mayor parte de los textos de la Constitución de 1925 que aún existen en las bibliotecas de abogados, están casi nuevos. Y ello, porque el texto de la Constitución era requerido mientras estudiábamos primer año de derecho (...). ${ }^{46}$

\section{c) Desde la segunda mitad del s.XX hasta hoy:}

Esta tercera etapa del pensamiento constitucional bien podría ser calificada como la síntesis de algunos aspectos relevantes de las dos anteriores. Por un lado, se advierte una creciente preocupación por los derechos fundamentales, los que, incluso, pasan a formar parte del lenguaje común bajo la denominación de "derechos humanos"; y por otra, la magnitud de los aparatos estatales sigue engrosándose haciéndose necesaria una especial atención constitucional sobre este punto, que ha tomado el nombre de Estado Benefactor o Estado Social de Derecho ${ }^{47}$. El constitucionalismo contemporáneo, por tanto, de distingue por una especial complejidad a ala que naturalmente también subyacen una serie de nuevos panoramas y procesos sociales cada vez más acelerados, ausentes del todo hasta la primera mitad del siglo pasado. Intentaremos describir brevemente, algunas de las manifestaciones más relevantes del pensamiento constitucional contemporáneo:

\section{a) Una jurisprudencia constitucional de fondo}

Zagrebelsky opina que " $[\mathrm{H}]$ oy, ciertamente, los jueces tienen una gran responsabilidad en la vida del derecho desconocida en los ordenamientos del Estado de derecho legislativo. Pero los jueces no son los señores del derecho en el mismo sentido en que lo era el legislador en el pasado siglo (s.XIX). Son más bien lo garantes de la complejidad estructural del derecho en el Estado constitucional, es decir, los garantes de la necesaria y dúctil coexistencia entre ley, derechos y justicia" 48 . El giro producido en la aplicación directa de la Constitución y el reconocimiento de su superioridad material dentro del ordenamiento jurídico, lleva hoy a que la Constitución sea invocada directamente por los particulares solicitando pronunciamientos de fondo sobre asuntos de relevancia constitucional. En Chile, esta tendencia alarma a ciertos juristas, toda vez que la vía constitucional se ha prestado para saltarse los mecanismos procesales y jurisdiccionales específicos so pretexto de proceder nuestro Recurso de Protección ${ }^{49}$. Pero, independiente de los posibles abusos a los que se pueda estar llegando, lo cierto es que la jurisprudencia constitucional ha permitido incorporar en el foro jurídico nacional nuevos conceptos jurídicos y una visión más garantista de nuestro ordenamiento. Además, como es lógico, para los fines del constitucionalismo es preferible un exceso de protección, incluso el indeseable abuso del derecho, que una estado de indefensión jurídica.

\section{b) El auge de la interpretación constitucional}

La indeterminación de las normas constitucionales unida a la posibilidad de ser aplicadas directamente, incluso, sin necesidad de mediar desarrollo legislativo o reglamentario, ${ }^{50}$ han hecho del

\footnotetext{
46 DOMÍNGUEZ A., RAMÓN, La constitucionalización del derecho, en 20 años de la Constitución cbilena: 1981-2001, Santiago, Ed. Conosur, 2001, p. 38.

${ }^{47}$ No pretendemos equiparar los términos, distintos entre sí, sino solamente utilizarlos en esta ocasión a modo de manifestaciones constitucionales que son efecto del crecimiento actual del Estado.

48 ZAGREBELSKY, GUSTAVO, op. cit., p. 153.

${ }^{49}$ Cfr. JANA LINETZKY, ANDRÉS, La eficacia horizontal de los derechos fundamentales, en SELA, 2001.

${ }^{50}$ FAVORES, LOUIS, op.cit., p. 35. Desarrolla allí uno de aparentes obstáculos a la constitucionalización del derecho, la teoría de la "pantalla legislativa". En efecto, "Esta técnica la usa sobre todo el juez administrativo: le permite rehusarse a examinar la constitucionalidad de un acto administrativo con el motivo que, ya que este acto descansa en una disposición legislativa, y
} 
problema de la interpretación uno de los centros de producción doctrinales más profusos y de mayor actualidad para el derecho constitucional. La trascendencia del tema no es menor toda vez que del método adoptado, que permita darle a las normas constitucionales mayor o menos extensión, o bien, la aceptación de los principios constitucionales inherentes a la carta como elementos de interpretación, se podrían aumentar o disminuir los criterios de inconstitucionalidad de las normas infraconstitucionales, o, incluso, llegar a soluciones diferentes para casos similares.

No se puede desatender en este punto la creciente relevancia que han ido adquiriendo los tribunales constitucionales y la justicia constitucional de los tribunales superiores de justicia, a los que se ha encomendado la misión de "concretizar" 51 las normas constitucionales de principio como determinar el alcance de los valores constitucionales. Como consecuencia de este inusitado auge de la interpretación constitucional la doctrina ha elaborado ciertas expresiones que buscan reflejar el fenómeno en cuestión. Por ejemplo, Konrad Hesse, habla de una interpretación "conforme a la Constitución", como presupuesto básico para cualquier interpretación normativa que se lleve a cabo. Corral la define del siguiente modo: "consiste en privilegiar como lectura de un texto legal aquella en que se aprecie mejor su compatibilidad con los valores y normas constitucionales. Igualmente se aplica esta vía cuando el intérprete se encuentra con cláusulas generales o abiertas en la descripción de los supuestos de hecho de las normas" 52 . Pero existen también posiciones más extremas o radicales, que hacen de las normas civiles el vehículo "el instrumento de actuación de los principios constitucionales" 53, "[e]s decir, que la Constitución y sus principios no deben influir en el Derecho civil, 'desde fuera' -a la manera en que es externa la luz al libro cuya 'relectura' se pretende -, sino que debe penetrar en el interior mismo del sistema, y desde ahí vitalizar enteramente el Derecho civil, constituyéndose en la fuerza interna inspiradora de la aplicación e interpretación de las normas civiles" ${ }^{54}$.

\section{c) Las aproximaciones a la filosofía del derecho}

El derecho constitucional ha vivido una gradual aproximación a la filosofía del derecho desde el momento en que su objeto principal de atención dejó de ser la llamada "Constitución”orgánica" y pasó a ser la "Constitución dogmática", en la terminología utilizada por Carl Schmitt, se prestó mayor atención a "Constitución" que a las "leyes constitucionales" 55 . Por lo demás, el problema de la fundamentación de los derechos humanos y los alcances de la libertad y la igualdad han cobrado desde la segunda mitad del siglo XX gran relevancia para los constitucionalistas, quienes han debido echar mano de la filosofía para aportar respuestas que exceden de lo directamente jurídico.

Estas características, brevemente desarrolladas aquí, ponen de manifiesto no sólo una transformación del pensamiento constitucional vigente, sino que son también fruto de una tendencia general en el derecho a ampliar las fronteras de "lo jurídico" cercenadas por el positivismo legalista, por un lado, y por otro, de la necesidad de comenzar a considerar al derecho (incluido el derecho constitucional) como un proceso en movimiento, cuyo motor antes que en el legislador está en la judicatura, superándose la visión estática defendida a rajatabla por las corrientes positivistas más ortodoxas.

teniendo entonces la ley el efecto de una pantalla entre el acto administrativo y la Constitución, le es imposible operar un control porque sino lo conduciría a apreciar la constitucionalidad de la ley lo que le es prohibida".

${ }^{51}$ Cfr. HESSE, KONRAD, Escritos de Derecho Constitucional, Centro de Estudios Constitucionales, Madrid, 1983, p.45.

52 CORRAL, HERNÁN, Algunas reflexiones sobre la constitucionalización del derecho privado, en Revista de Derecho Universidad Mayor, Año 3, Vol. 3, 2004, p. 56-57.

${ }^{53} \mathrm{Idem}$.

${ }^{54}$ MARTÍNEZ DE AGUIRRE, CARLOS, El derecho civil a finales del siglo XX, Tecnos, Madrid, 1991, p. 85. La cita se encuentra también en el trabajo de Hernán Corral previamente citado.

${ }^{55}$ Cfr. SCHMITT, CARL, Teoría de la Constitución, Alianza Editorial, Madrid, 1992, p. 63 y ss. 


\section{III. ¿Un retorno a los principios o al Derecho Natural?}

La afirmación inicial de este trabajo sobre el cambio producido en el sistema de fuentes del derecho por la irrupción del fenómeno llamado constitucionalización del derecho podría ser sometida a una interrogante adicional que por los demás no deja de ser audaz vistas las contrareacción que dentro de la doctrina del derecho inmediatamente produce la afirmación sobre la existencia de un derecho no creado, de un derecho natural. La pregunta es si este proceso implica un retorno al reconocimiento y vigencia del derecho preestatal -derecho natural- o, en cambio, constituye más bien la recepción dentro del razonamiento jurídico de los principios de derecho positivo. En otro términos podría también preguntarse "qué lugar ocupa el llamado 'derecho natural' en el sistema jurídico contemporáneo? Dada la actual situación de las fuentes del derecho, ¿cabe pensar todavía en el 'derecho natural' como en un patrón abstracto de justicia, con el que se valora un 'derecho positivo' que es el derecho 'proprie dicto'? ¿Se ha de concebir al 'derecho natural' como un 'ideal de justicia' o como verdadero derecho vigente? En otras palabras: la vigencia de criterios 'suprapositivos' de justicia, ¿es un idea ético, político o jurídico?”56.

\section{a) La tesis de Zagrebelsky}

La tesis de Gustavo Zagrebelsky es la del funcionamiento del sistema jurídico moderno sobre normas de principio que dan la impresión "como si rigiese un derecho natural". De lo que resulta que para el autor la tendencia del derecho moderno es a "ductilizarse" (por utilizar la terminología que da pie al título de su libro) mediante la temperación por principios sujetos a las reglas del pluralismo social. Es cierto que entre los principios y el derecho natural existe una cierta analogía de estructuración y que, por de pronto, ambos no se agotan en la norma meramente positivizada ${ }^{57}$, pero la corriente jurídica moderna no iría en la dirección de un regreso al reconocimiento de preceptos de derecho natural aplicables por el juez, sino más bien, de principios positivos contenidos en la más alta norma positiva, la Constitución. "Así pues, cabe decir en síntesis que la Constitución no es derecho natural sino la manifestación más alta del derecho positivo. Sin embargo, dado que el derecho constitucional se presenta no como la voluntad de una parte que se impone sobre la otra, sino como expresión de un equilibrio objetivo (...), la relación entre la ley [ley constitucional incluida] y la Constitución se aproxima a la relación entre ley y derecho natural"

A juicio del autor, las actuales circunstancias políticas y el secularismo comúnmente aceptado harían del reconocimiento de la esencia "natural" de estos principios algo inaceptable. En efecto, "[l]a confirmación política de la naturaleza de estas normas [constitucionales de principios] está en el hecho de que, por lo general, las constituciones se aprueban, si no por unanimidad, al menos por amplísima mayoría (...), se podría decir que las constituciones reflejan el 'orden natural' histórico-concreto de las sociedades políticas secularizadas y pluralistas, en las que, precisamente por ello, no podía proponerse de nuevo un derecho natural con fundamento teológico ni racionalista". ${ }^{59}$

Con todo, lo que se impone en su tesis es la insuficiencia del positivismo jurídico de satisfacer las demandas de justicias actuales, como también de carecer de una metodología suficientemente compleja como para llegar a soluciones adecuadas en el plano concreto. "Concebidos como perfeccionamiento del ordenamiento jurídico [los principios según la teoría positivista], los principios des-

\footnotetext{
${ }^{56}$ ORREGO S, CRISTÓBAL, "El lugar del derecho natural en el sistema de fuentes del derecho en el siglo XX", en Interpretación, integración y razonamiento jurídicos, Ed. Jurídica de Chile, Santiago, 1991, p., 160.

${ }^{57}$ Aunque para Zagrebelsky los principios son norma positiva su contenido no se termina en la enunciación semántica que se haga de él.

${ }^{58}$ ZAGREBELSKY, GUSTAVO, op. cit., p. 116

${ }^{59}$ Idem., p. 115.
} 
empeñan una función en la práctica del derecho. Sin embargo, esta concepción no solo es parcial, como se dirá de inmediato, sino que encierra además la intrínseca contradicción de asignar a las normas de mayor densidad de contenido -los principios- una función puramente accesoria de la que desempeñan las normas cuya densidad es menor -las reglas-. Esto deriva del persistente prejuicio de pensar que, en realidad, las verdaderas normas son las reglas, mientras que los principios son un 'plus', algo que sólo es necesario como 'vávula de seguridad' del ordenamiento. Una vez más, el positivismo se revela como una ideología distorsionada en el campo del derecho"60.

En síntesis, la tesis de la Zabgrebelsky puede denominarse como una versión moderada acerca de la aceptación del derecho natural en nuestro sistema de fuentes. A su juicio, la ubicación de éste cabe en tanto analogía dentro de las normas constitucionales de principio, pero sólo en tanto que analogía, pues una aceptación directa de ellos podría transgredir la secularidad propia de las sociedades multiculturales. ${ }^{61}$ Con todo, su pensamiento en este punto implica un paso en la superación de los esquemas meramente legalistas que durante años predominaron en la doctrina jurídica general.

\section{b) Una tendencia: el reconocimiento y la aplicación de los principios}

Si bien es cierto que la doctrina ha tendido a considerar últimamente al derecho legislado como parte del derecho total y no como el único derecho vigente, la actual situación no permite asentar la tesis de una aceptación expresa del derecho natural como fuente sin más. Sería pecar de exceso de optimismo, y aprovechar esta crisis de la ley para traer agua al propio molino. Sin embargo, no deja de ser cierto que se ha producido una apertura positiva hacia los principios "no escritos" lo que se manifiesta tanto en la jurisprudencia como en las mismas técnicas de legislación. Sobre estas últimas destaca la tendencia del derecho comparado a incluir capítulos iniciales en las leyes donde se contienen los principios rectores de dicha normativa pudiendo el juez hacer uso de ellos para complementar la aplicación "seca" de la ley. En nuestro medio, a modo de ejemplo, destacan la gran cantidad de principios incluidos en el Código Procesal Penal, como también en la reciente Ley de Procedimiento Administrativo.

¿Agota la Constitución los principios de derecho? ¿Es acaso su única y última fuente? Nos parece extrema la posición que tiende a dar esta categoría omniabarcante al documento constitucional, y que daría pie para que de su interpretación pudiesen ir derivándose principios encontrando todos ellos su origen primero en las disposiciones constitucionales. O lo que podría ser otra formulación de la misma figura, la "autarquía constitucional", que como señala Hernán Corral es el método utilizado para aplicar directamente la Constitución previa fabricación intencionada de una laguna legal por parte del intérprete para que a falta de ley puedan aplicarse de forma directa los principios de la Constitución. La técnica, con todo, se presta para una fraude interpretativo, ya que, "como la Constitución no contiene propiamente un régimen jurídico que sea capaz de abordar completamente es materia [sobre la que existe una supuesta laguna] entonces se siente libre el intérprete para establecer como reglas propias de ese régimen aquellas que, según él, deben deducirse del silencio del constituyente" 62 . Al contrario, parece más adecuado, así lo creemos, afirmar que la Constitución selecciona determinados principios jurídico y los hace objeto de preferencia en su aplicación, promoción y también protección. De modo que "la constitucionalización de la categoría de los principios generales no significa, en modo alguno, que con la Constitución hayan desaparecidos estos de nuestro ordenamiento. El juez ordinario puede y debe seguir acudiendo a ellos para llenar las lagunas del ordenamiento, interpretar

\footnotetext{
${ }^{60}$ Idem., p. 117.

${ }^{61}$ Acerca del carácter no exclusivamente religioso de los preceptos de derecho natural, véase, HERVADA, JAVIER, op. cit., p. 100 y ss.

${ }^{62}$ CORRAL, HERNÁN, op. cit., p. 59.
} 
las leyes, e incluso excepcionar su aplicación en el caso concreto (...)"63. Para los efectos de nuestra tesis, lo relevante es que gracias a los principios constitucionales y su aplicabilidad, hoy día se ha puesto más de moda el "derecho de principios" que el "derecho de normas o reglas"; los operadores del derecho vieron en las categorías constitucionales un salvavidas para salir el entramado legalista y poder comenzar a hacer ciencia jurídica y a resolver los casos con justicia y no lógica. Salir al paso de los riesgos de la indeterminación y el voluntarismo judicial que un derecho de principios puede causar será la tarea más próxima que la doctrina deberá abordar con rigurosidad metodológica y la jurisprudencia de los tribunales delimitar en sus contornos.

Hasta la fecha han sido en Chile los jueces de protección quienes han debido cargar con la responsabilidad de hacer aplicables las normas de principios constitucionales y de recurrir a ellas para terminar con actuaciones ilegales o arbitrarias. Sin embargo, no puede decirse que la gran cantidad de recursos deducido y resueltos haya ido a la par de un desarrollo jurisprudencial sólido sobre los principios constitucionales. Actualmente se vive una dispersión jurisprudencial que a veces llega, incluso, a ser contradictoria. Los riesgos de un Estado de Derecho así son evidentes: se termina por hacer justicia a la carta. Por eso un autor ha señalado, sobre este punto, la importancia de los criterios de razonabilidad de las decisiones jurisdiccionales en materia constitucional, por los que "el razonamiento judicial empleado por los jueces de protección se debe traducir en una decisión razonable, esto es, aquella decisión capaz de ser justificada razonable y coherentemente con el ordenamiento jurídico general, especialmente constitucional. Con el consecuente abandono en sur razonamiento de cualquier atisbo de positivismo legalista"'64.

\section{Referencias bibliográficas}

ALEXY, ROBERT, Teoría de la argumentación juridica, Centro de Estudios Constitucionales, Madrid, 1997

BENADAVA, SANTIAGO, Derecho Internacional Público, Ed. Conosur, séptima edición, Santiago, 2001

CAZOR A., KAMEL, El fenómeno de la constitucionalización del Derecho: cuestiones de mera legalidad, de trascendencia constitucional y derechos fundamentales, en La constitucionalización del derecho chileno, Ed. Jurídica de Chile, Santiago, 2004

CEA, JOSÉ LUIS, La constitucionalización del derecho, en Revista de Derecho Público, No 59, 1996

CORRAL, HERNÁN, Algunas reflexiones sobre la constitucionalización del derecho privado, en Revista de Derecho Universidad Mayor, Año 3, Vol. 3, 2004

CORREA G., RODRIGO, ¿Vulgarización por constitucionalización?, en Revista de Derecho y Humanismo, Universidad de Chile, Vol XI, 2005

D’ORS, ALVARO, Derecho Privado Romano, Eunsa, Novena edición, Pamplona, 1997

DE OTTO, IGNACIO, Derecho Constitucional. Sistema de fuentes, Ed. Ariel, Segunda edición, Barcelona, 1988

DOMÍNGUEZ A., RAMÓN, La constitucionalización del derecho, en 20 años de la Constitución chilena: 19812001, Santiago, Ed. Conosur, 2001

ERRÁZURIZ M., CARLOS J., Introducción crítica a la doctrina jurídica de Kelsen, Ed. Jurídica de Chile, Santiago, 1987

FAVOREU, LOUIS, La constitucionalización del derecho, en Revista de Derecho Universidad Austral, Vol. XII, 2001

${ }^{63}$ RUBIO LLORENTE, FRANCISCO, Principios y valores constitucionales, en Estudios de Derecho Constitucional, Homenaje al profesor Rodrigo Fernández-Carvajal, Murcia, Universidad de Murcia, 1997, p. 660.

${ }^{64}$ CAZOR A., KAMEL, El fenómeno de la constitucionalización del Derecho: cuestiones de mera legalidad, de trascendencia constitucional y derechos fundamentales, en La constitucionalización del derecho chileno, Ed. Jurídica de Chile, Santiago, 2004, p. 30. 
GARCÍA PELAYO, MANUEL, Derecho constitucional comparado, Alianza Editorial, Madrid, 1987, HERVADA, JAVIER, Introducción crítica al derecho natural, Colección jurídica de la Universidad de Piura, primera edición peruana, Piura, 1999

HESSE, KONRAD, Escritos de Derecho Constitucional, Centro de Estudios Constitucionales, Madrid, 1983

HÜBNER G, JORGE, Introducción al Derecho, Ed. Jurídica de Chile, Colección de Manuales Jurídicos, Séptima edición, Santiago, 1995

JANA LINETZKY, ANDRÉS, La eficacia horizontal de los derechos fundamentales, en SELA, 2001.

JOHN FINNIS, en Ley natural y derechos naturales, Buenos Aires, Abeledo-Perrot, 2001

JUSTO LÓPEZ, MARIO, Manual de derecho politico, Ed. Kapelusz, Buenos Aires, 1973

LASALLE, FERDINAND, ¿Qué es una Constitución?, Editorial Temis, Bogotá, 1992

LOEWENSTEIN, KARL, Teoría de la Constitución, Ed. Ariel, Segunda edición, Barcelona, 1986

MARTÍNEZ DE AGUIRRE, CARLOS, El derecho civil a finales del siglo XX, Tecnos, Madrid, 1991

OLLERO, ANDRÉS, Interpretación del derecho y positivismo legalista, Editoriales de Derecho Reunidas, Madrid, 1982

ORREGO S., CRISTÓBAL, El lugar del derecho natural en el sistema de fuentes del derecho en el siglo XX, en Interpretación, integración y razonamiento jurídicos, Ed. Jurídica de Chile, Santiago, 1991

ORREGO S., CRISTÓBAL, De la ontología del derecho al derecho justo. Progresos recientes de la teoría analítica del derecho, en Revista Chilena de Derecho, Vol. 30 Nº 2, 2003

ORREGO S., CRISTÓBAL, La cultura jurídica interna: ¿Hacia el colapso de la pirámide?, en Anuario de Filosofía Jurídica y Social, Valparaíso, 2002

PEREIRA MENAUT, ANTONIO CARLOS, Rule of Law o Estado de Derecho, Marcial Pons Ediciones Jurídica y Sociales, Madrid, 2003

PEREIRA MENAUT, ANTONIO CARLOS, Teoría Constitucional, Ed. Conosur, Santiago, 1998

RUBIO LLORENTE, FRANCISCO, Principios y valores constitucionales, en Estudios de Derecho Constitucional, Homenaje al profesor Rodrigo Fernández-Carvajal, Murcia, Universidad de Murcia, 1997

SCHMITT, CARL, Teoria de la Constitución, Alianza Editorial, Madrid, 1992

SILVA BASCUÑAN, ALEJANDRO, Tratado de Derecho Constitucional, Tomo I, Ed. Jurídica de Chile, Segunda edición, Santiago, 1997

SOTO KLOSS, EDUARDO, Derecho Administrativo, Bases fundamentales. Vol. II: El principio de juridicidad, Ed. Jurídica de Chile, Santiago, 1996

ZAGREBELSKY, GUSTAVO, El derecho dúctil, Trotta, Madrid, 1995. 